Arthroscopic surgery of the knee demands an exacting and skilled technique and a degree of patience and perseverence which is not a characteristic of every orthopaedic surgeon. A sound knowledge of diagnostic arthroscopy is needed before a surgeon moves on to operative arthroscopy. Once he has mastered the skills, however, there are considerable benefits for the patient - and his or her employer-and economic advantages for the NHS.

Early in the development of arthroscopy simple manoeuvres such as synovial biopsy, synovial shelf excision, or the removal of loose or foreign bodies from within the joint were found to cause little difficulty. More refined instruments made more complex operations possible. It is, however, the surgery of the menisci which has been altered most dramatically by the advent of operative arthroscopy. The technical innovations came at a time when a more conservative approach was developing towards excision of the menisci. Use of the operating arthroscope with new, stronger instruments allows the surgeon to deal with flap tears, bucket handle tears, tears of the anterior and posterior attachments, and other miscellaneous lesions without the need to open the joint extensively. Shaving and drilling of the patella and abrasion or drilling of chondral defects elsewhere in the knee are also possible. More complex procedures have been attempted, including fixing osteochrondral fragments, synovectomy for rheumatoid or haemophilic synovitis, ${ }^{5}$ total meniscectomy, and the endoscopic repair of peripheral meniscal detachments. Metcalf has categorised arthroscopically treatable lesions in a useful way, listing them in order of progressive difficulty from the surgeon's point of view. ${ }^{6}$

Most orthopaedic surgeons now accept that a meniscus should be removed only when it is known to be abnormal. ${ }^{7}$ Partial meniscectomy with removal of unstable fragments and preservation of as much of the meniscus as possible is the operation of choice, but it demands accurate diagnosis. A combination of clinical impression and arthroscopy can produce a diagnostic accuracy of $95 \%$, and when combined with arthrography this can be improved to $97 \% .^{8}$

Arthroscopic surgery has obvious advantages over open arthrotomy: these include preference by the patient and rapid rehabilitation and discharge from hospital. A study in 1984 of American soldiers showed a reduction of time in hospital of $32 \%$ with an annual saving to the army of over $\$ 5.5 \mathrm{~m} . .^{9}$ Average inpatient stays of between one day ${ }^{10}$ and two and a half days ${ }^{11}$ have been reported. As experience is gained some patients may be treated as day cases. The length of time taken off work in many reported series is in the region of 12 to 14 days compared with six to eight weeks or more after an open operation.

Complications of the procedure are remarkably few. In a series of 230 patients treated by surgeons of widely differing experience in whom open and arthroscopic meniscectomy was compared Simpson et al found no complications in the arthroscopic group; in the open group, on the other hand, there were two cases of deep venous thrombosis, two of haematoma, and one of wound dehiscence. ${ }^{12}$ Instruments may break, but the fragments may usually be retrieved arthroscopically. ${ }^{11}$ Infection after arthroscopy is almost unknown-and in view of the dubious sterility achieved during the procedure this is surprising to a degree which warrants further inquiry. ${ }^{5}$ Nevertheless, the greatest care must be taken to prevent contamination of instruments during surgery.

In the short term skilfully performed arthroscopic surgery can undoubtedly bring great therapeutic benefit. It remains to be seen, however, whether in the long term the procedure lives up to its early expectations in respect of meniscal surgery. This less destructive method of removing a troublesome fragment of meniscus may seem to be the best way, but, as Goodfellow has wisely pointed out, "It would be a pity if the liberty to operate by closed methods should be misinterpreted as a licence to operate too often." ${ }^{13}$ Only when patients who are being treated now by closed partial meniscectomy have been followed up for 20 years or more will it be known whether the long term risk has been avoided-osteoarthrosis after meniscal injury.

S C GALlanNAUGH

Consultant Orthopaedic Surgeon,

Royal East Sussex Hospital,

Hastings TN34 1ER

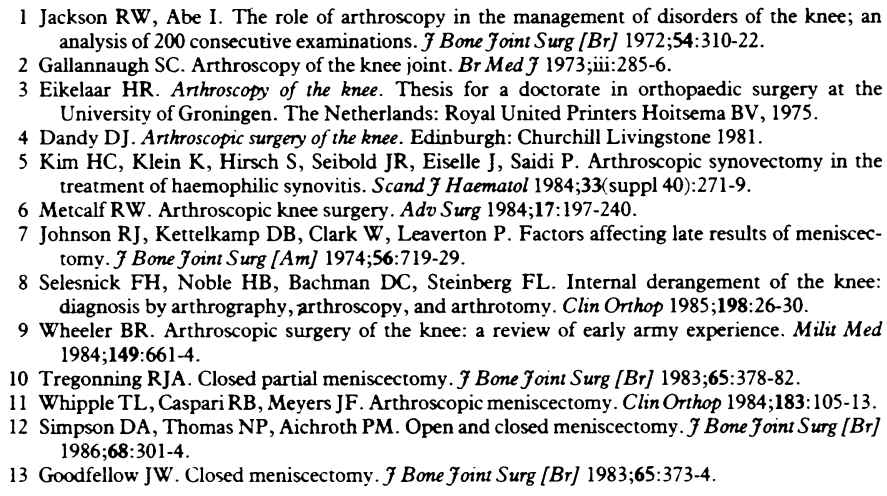

1 Jackson RW, Abe I. The role of arthroscopy in the management of disorders of the knee; an analysis of 200 consecutive examinations. F Bone foint Surg $[B r]$ 1972;54:310-22. analysis of 200 consecutive examinations. F Bone foint Surg (Br] 1972,54:3
Gallannaugh SC. Arthroscopy of the knee joint. Br Med f 1973;iii:285-6.

3 Eikelaar HR. Arthroscopy of the knee. Thesis for a doctorate in orthopaedic surgery at the University of Groningen. The Netherlands: Royal United Printers Hoitsema BV, 1975

Dandy DJ. Arthroscopic surgery of the knee. Edinburgh: Churchill Livingstone 1981.

5 Kim HC, Klein K, Hirsch S, Seibold JR, Eiselle J, Saidi P. Arthroscopic synovectomy in the treatment of haemophilic synovitis. Scand f Haematol 1984;33(suppl 40):271-9.

Metcalf RW. Arthroscopic knee surgery. Adv Surg 1984;17:197-240.

7 Johnson RJ, Kettelkamp DB, Clark W, Leaverton P. Factors affecting late results of meniscectomy. F Bone foint Surg $[$ Am] 1974;56:719-29.

Selesnick FH, Noble HB, Bachman DC, Steinberg FL. Internal derangement of the knee: diagnosis by arthrography, arthroscopy, and arthrotomy. Clin Orthop 1985;198:26-30. Wheeler BR. Arthroscopic surgery of the knee: a review of early army experience. Milit Med 1984;149:661-4.

10 Tregonning RJA. Closed partial meniscectomy. I Bone foint Surg [Br] 1983;65:378-82.

11 Whipple TL, Caspari RB, Meyers JF. Arthroscopic meniscectomy. Clin Orthop 1984;183:105-13.

12 Simpson DA, Thomas NP, Aichroth PM. Open and closed meniscectomy. $\mathcal{F}$ Bone foint Surg [Br] 1986;68:301-4.

13 Goodfellow JW. Closed meniscectomy. F Bone foint Surg [Br] 1983;65:373-4

\section{Prenatal diagnosis of the Turner syndrome: what to tell the parents}

Each year in Britain there are over 23000 amniocenteses and these result in about 12 fortuitous diagnoses of the Turner syndrome. This number will rise as chorionic villus sampling is used more widely. What should the parents be told in such circumstances?

Most cases of the Turner syndrome are due to a missing sex chromosome to leave the constitution $45, \mathrm{X}$ or monosomy X. It is one of the commonest chromosomal disorders, occurring in about 150 of every 10000 conceptions. ${ }^{1}$ Most of these embryos abort spontaneously, however, and by the second trimester the incidence has fallen to 9 in every 10000 female fetuses in mothers over $35,{ }^{2}$ and by birth it is 1 in 10000 girls. ${ }^{3}$ The cause of this wastage is unknown but may relate to delayed opening of the jugular lymph sac into the jugular vein, which has normally occurred by 8 weeks' gestation. During the second trimester this may be apparent on an ultrasound scan as nuchal cystic hygromas and if associated with chlothorax and ascites carries a grave prognosis. ${ }^{4}$ An additional factor might be the placenta, which is typically hypoplastic with small hypervascular villi. ${ }^{5}$ The fetuses that survive may show neonatal sequelae of lymphatic obstruction with redundant neck skin or webbing, peripheral lymphoedema, deep set nails, and a predominance of finger tip whorls. $^{6}$

Congenital malformations are common in girls with the Turner syndrome: coarctation of the aorta or other congenital heart disease occurs in a fifth and a variety of usually 
non-lethal renal malformations in a half. Mild growth retardation is apparent in utero. The girls fall further behind during childhood and there will be no pubertal spurt. ${ }^{7}$ Lyon and others have derived useful growth charts from 355 untreated European patients and found a mean adult height of $143 \mathrm{~cm}(4 \mathrm{ft} 9$ in) with a standard deviation of $6.7 \mathrm{~cm}$, which was not significantly different from that of their patients on oestrogen replacement treatment. ${ }^{8}$

Earlier worries about an increased risk of mental retardation were unfounded: there is a normal distribution of full scale intelligence quotients, but verbal ability tends to exceed performance. Characteristically there are space-form perceptual difficulties on detailed psychological testing. ${ }^{9}$

The histological appearance of the ovaries is normal in the fetus, but they later degenerate to streaks devoid of primordial follicles. ${ }^{10}$ In about $3 \%$ of affected girls the degeneration is incomplete in adolescence, and a patient with 45, X may menstruate for a few years, and, exceptionally, successful pregnancy may occur. ${ }^{11}$ Usually, however, secondary sexual characteristics do not develop and the girls are infertile. Hormone replacement treatment will induce sexual characteristics, and the infertility might be amenable to in vitro fertilisation with a donor egg.

Systemic hypertension is common especially in the older patient, ${ }^{12}$ and there is a small but definite increased risk of aortic dissection even without hypertension or previous coarctation..$^{13}$ Osteoporosis is common but usually asymptomatic. ${ }^{14}$ Other rare complications include gastrointestinal haemorrhage, ${ }^{15}$ diabetes mellitus, autoimmune thyroiditis, keloids, and hearing loss secondary to recurrent otitis media. Lifespan is otherwise probably normal, although longitudinal studies to prove this are not yet available.

Although the commonest cause is $45, \mathrm{X}$, a variety of other sex chromosomal problems can produce a similar or milder phenotype, especially where normal cell lines coexist. ${ }^{31617}$ The pathogenesis in each reflects $\mathrm{X}$ chromosmal gene dosage imbalance: as normally in the female lyonisation inactivates all of one $\mathrm{X}$ with the exception of genes near the tip of the short arm, these genes are prime aetiological candidates and are currently under investigation with recombinant DNA techniques. ${ }^{18}$

In our experience most couples when presented with all this information elect to continue the pregnancy, but it is important to emphasise the high spontaneous wastage: less than a fifth of fetuses with $45, \mathrm{X}$ diagnosed at amniocentesis will survive to term, and after prenatal diagnosis in the first trimester probably less than $1 \%$ will survive.

J M CONNOR

Wellcome Trust Senior Lecturer,

West of Scotland Regional Genetics Centre

Duncan Guthrie Institute of Medical Genetics,

Glasgow G3 8S

1 Warburton D, Stein Z, Kline J, Susser M. Chromosome abnormalities in spontaneous abortions: data from the New York City study. In: Porter IH, Hook GB, eds. Human embryonic and fetal death. New York: Academic Press, 1981:261-87.

2 Ferguson-Smith MA, Yates JRW. Maternal age-specific rates for chromosome aberrations and factors influencing them: report of a collaborative European study on 52965 amniocenteses. Prenat Diagn 1984;4:5-44.

3 Hook EB, Warburton D. The distribution of chromosomal genotypes associated with Turner's syndrome: livebirth prevalence rates and evidence for diminished fetal mortality in genotypes associated with structural $X$ abnormalities or mosaicism. Hum Genet 1983;64:24-7.

4 Chervenak FA, Isaacson G, Blakemore $\mathrm{KJ}$, et al. Fetal cystic hygroma. Cause and natural history. N Engl f Med 1983;309:822-5.

5 Honore LH, Dill FJ, Poland BJ. Placental morphology in spontaneous human abortuses with normal and abnormal karyotypes. Teratology 1976;14:151-66.

6 Smith DW. Recognisable patterns of human malformation. 3rd ed. Philadelphia: Saunders, 1982.

7 Brook CGD. Turner syndrome. Arch Dis Child 1986;61:305-9.

8 Lyon AJ, Preece MA, Grant DB. Growth curve for girls with Turner syndrome. Arch Dis Child 1985;60:932-5.

9 Pidcock FS. Intellectual functioning in Turner syndrome. Deo Med Child Neurol 1984;26:539-45.

10 Weiss L. Additional evidence of gradual loss of germ cells in the pathogenesis of streak ovaries in Turner's syndrome. 7 Med Genet 1971;8:540-4.

11 Wray HL, Freeman MVR, Ming PML. Pregnancy in the Turner syndrome with only 45,X ray HL, Freeman MVR, Ming PML. Pregnancy in
12 Sybert VP, Hall JG. Turner syndrome: natural history in the older woman. Am $\mathcal{F}$ Hum Genet 1979;31:85A.

13 Price WH, Wilson J. Dissection of the aorta in Turner's syndrome. $\mathcal{F}$ Med Genet 1983;20:61-3. Smith MA, Wilson J, Price WH. Bone demineralisation in patients with Turner's syndrome. $f$ Med Genet 1982;19:100-3.

15 Burge DM, Middleton AW, Kamath R, Fasher BJ. Intestinal haemorrhage in Turner's syndrome. Arch Dis Child 1981;56:557-8.

16 Ferguson-Smith MA. Karyotype-phenotype correlations in gonadal dysgenesis and their bearing on the pathogenesis of malformations. $\mathcal{F}$ Med Genet 1965;2:142-55.

17 Simpson L. Disorders of sexual differentiation. New York: Academic Press, 1976.

18 Davies KE. Molecular genetics of the human X chromosome. I Med Genet 1985;22:243-9.

\section{The flexible fibreoptic rhinolaryngoscope}

In 1970 Silberman found that a flexible bronchoscope gave a satisfactory view of the nasopharynx and larynx. ${ }^{1}$ In 1968 Sawashima had described a flexible laryngoscope,${ }^{2}$ but it was not until 1973 that a flexible fibreoptic laryngoscope became commercially available. ${ }^{3}$ This had a large tip (diameter $6.25 \mathrm{~mm}$ ) and was designed as an aid for difficult anaesthetic intubations-but its large diameter also made it impracticable to use for diagnostic otolaryngology.

In 1975 Silberman described a nasopharyngolaryngoscope with a small external diameter of $3.9 \mathrm{~mm}$ but with a larger optical bundle than the flexible bronchoscope. ${ }^{45}$ The small tip made it easy to introduce the instrument through the nasal cavity - but the instrument did not include an aspiration channel. In practice this was unimportant, as secretions which prevented an adequate view could be cleared by asking the patient to swallow. A biopsy channel perhaps would be a useful facility but that, too, would increase the tip diameter.

Over the past few years the diameter of the tip has gradually decreased, and the most recent model, the Olympus ENF-P2, has an external tip diameter of $3.4 \mathrm{~mm}$, an $85^{\circ}$ field of view, a tip movement range of $230^{\circ}$, and a working length of $255 \mathrm{~mm}$.

The flexible rhinolaryngoscope is used to assess both the structure and function of the upper respiratory tract. Originally only the larynx and pyriform fossae could be examined, ${ }^{6}$ but with the most recent endoscopes all areas from the nasal vestibule to the carina may be viewed with precision-including the sinus ostia, the roof of the nose, and the fossae of Rosenmuller. The orifice of the eustachian tube may be observed during opening and closure; velopalatine function is easily assessed; the tongue may be observed at rest and during protrusion; and the larynx may be seen at rest, during quiet and deep respiration, and during phonation.

Conventional otolaryngological practice has taught us to examine the nasopharynx, larynx, and laryngopharynx by indirect techniques. Nevertheless, in some patients-those who are over anxious, those who may have an easily excitable gag reflex, and those with a narrow nasopharyngeal isthmus or a prominent and overhanging epliglottis-a full and satisfactory assessment may not be possible with such methods. These are the patients in whom examination with the flexible fibreoptic rhinolaryngoscope will be of most value. Selkin has found that most young children will permit examination without sedation, ${ }^{7}$ but in our experience it is rarely possible in those under 8 years.

A recent review of 338 consecutive examinations found that in $57 \%$ no abnormality was seen. ${ }^{8}$ Patients in this 8 category may be reassured and discharged, thus saving a considerable amount of hospital time and expense. ${ }^{9}$ In the 